\title{
Randomised controlled trial of trophic feeding and gut motility
}

\author{
R J McClure, S J Newell
}

\begin{abstract}
Objectives-To determine the effect of trophic feeding on gastric emptying and whole gut transit time in sick preterm infants.

Methods-A randomised, controlled, prospective study of 70 infants weighing less than $1750 \mathrm{~g}$ at birth, who were receiving ventilatory support, was performed. Group TF (33 infants) received trophic feeding from day $3(0.5 \mathrm{ml} / \mathrm{h}$ if birthweight less than $1 \mathrm{~kg}, 1 \mathrm{ml} / \mathrm{h}$ if greater or equal to $1 \mathrm{~kg}$ ) in addition to parenteral nutrition until ventilatory support finished. Group C (37 infants) received parenteral nutrition alone until ventilatory support finished. Expressed breast milk or a preterm formula were given according to maternal preference. Gastric emptying was assessed within 24 hours of nutritive milk feeding equal to $90 \mathrm{ml} / \mathrm{kg} / \mathrm{day}$, using ultrasound scans to measure the reduction in the gastric antral cross sectional area after a feed. Whole gut motility was assessed at both 3 and 6 weeks of age by measuring the whole gut transit time (WGTT) of the marker carmine red.
\end{abstract}

Results-There was no significant difference between groups in their gastric half emptying time, median difference $(95 \%$ confidence interval) $2.6(-5.9,13.9)$ minutes. The WGTT was significantly faster $(\mathrm{p}<0.05)$ in group $\mathrm{TF}$ at both 3 and 6 weeks; median difference $-13(-47,-0.1)$ and $-12.5(-44,-0.5)$ hours, respectively. Conclusions-Trophic feeding enhances whole gut motility but not gastric emptying. This effect could subsequently improve milk tolerance in sick preterm infants. (Arch Dis Child Fetal Neonatal Ed 1999;80:F54-F58)

Keywords: trophic feeding; gut motility; parenteral feeding; gastric emptying

Neonatologists recognise the importance of providing optimal nutrition to sick preterm infants but differ in their choice of method to best meet this difficult objective. ${ }^{1}$ A standard practice is to provide all nutritional requirements parenterally until the infant is well enough to be fed milk. Parenteral nutrition provides a secure source of nutrition, independent of gut function, and may reduce the incidence of necrotising enterocolitis, ${ }^{2}{ }^{3}$ but is associated with several complications and drawbacks. ${ }^{4}$ Prolonged parenteral nutrition and enteral starvation has a deleterious effect on gut growth and development. ${ }^{56}$ Trophic feeding - minimal enteral feeding, gut priming, early hypocaloric feeding - is used to try and overcome this problem. The practice involves feeding small volumes of milk that are nutritionally insignificant but are thought to be of benefit to the developing gut. Typical volumes are 1 to $24 \mathrm{ml}$ daily/kg/body weight. ${ }^{7-11}$

Several small randomised studies suggest that trophic feeding improves subsequent tolerance of milk feeding. ${ }^{7-11}$ Evidence from manometric measurements has shown that trophic feeding results in earlier development of mature fasting proximal intestinal motility patterns. ${ }^{11}{ }^{12}$ The effect of trophic feeding on gastric emptying or more distal intestinal motility has not been studied.

We performed a study consisting of two parts to determine the response of later gastric emptying (part 1) and whole gut motility, measured by timing the whole gut transit of a liquid marker (part 2), to trophic feeding of sick preterm infants.

\section{Methods}

Consecutive preterm infants were recruited and studied on the regional neonatal intensive care unit, St James's University Hospital, Leeds. The routine policy on this unit was for all infants with respiratory distress syndrome of prematurity to receive total parenteral nutrition until ventilatory support was stopped, at which time milk feeding was introduced.

On day 3 of life, infants who satisfied all the following criteria were recruited into both parts of the study: gestation less than 37 completed weeks; birthweight less than $1750 \mathrm{~g}$; respiratory distress syndrome requiring ventilatory support beyond the second day; and in receipt of no enteral feeding. Infants were excluded if they had clinically significant congenital gastrointestinal pathology, a lethal congenital malformation, or if they were receiving drug treatment known to interfere directly with gastric or intestinal motility. Treatment with caffeine was not an exclusion criterion as its use was routine to prevent apnoea of prematurity. Infants left the study if they were transferred to another hospital for further medical care. Data obtained before discharge were included for analysis.

Using data from previous relevant studies ${ }^{13-15}$ the number of infants required to demonstrate a 10 minute difference in gastric emptying with $90 \%$ power was estimated at 40 . Similarly, using previous study data, ${ }^{16-18} 30$ infants was estimated as being required to demonstrate a 5 hour difference in the whole gut transit time (WGTT).

Informed parental consent was obtained before each infant was recrited to the study. The study was approved by the local research ethics committee. 
RANDOMISATION

The following protocol was applied to both parts of the study. To prevent chance sampling inequality, infants were stratified by gestation and birthweight ratio (defined as birthweight divided by the relevant 50 th centile value for weight for the gestational age at birth) before randomisation. Randomisation was then into one of two groups: TF (to receive trophic feeding as well as parenteral nutrition), or $\mathrm{C}$ (control group to receive parenteral nutrition alone). Randomisation was performed using computer software: minimisation program for allocating patients to treatments in clinical trials, Department of Clinical Epidemiology, The London Hospital Medical College.

\section{FEEDING SCHEDULE}

Trophic feeding in group TF was started on day 3 of life at the rate of $0.5 \mathrm{ml} /$ hour if birthweight was less than $1 \mathrm{~kg}$, or $1 \mathrm{ml} /$ hour if birthweight was equal or greater than $1 \mathrm{~kg}$. Expressed breast milk (EBM) or preterm formula milk (Nutriprem; Cow \& Gate Nutricia) was given according to maternal choice. If $\mathrm{EBM}$ was unavailable preterm formula was given. All milk was administered as hourly bolus feeds through a 5 or 6 French gauge silastic nasogastric tube (Vygon (UK) Ltd.). Trophic feeding was continued at the same rate until intermittent positive pressure ventilatory support stopped. Feeding was omitted while infants received continuous positive airway pressure (CPAP) support because of the possible increased risk of milk aspiration. Once ventilatory support was no longer required nutritive milk feeds were introduced and increased until full enteral feeding was established. The rate of increase was determined by feed tolerance and was at the discretion of the attending nurse, usually volume was increased by $1 \mathrm{ml}$ every 12 hours. EBM was fortified with a commercial preparation (Breast Milk Fortifier, Cow \& Gate Nutricia) once an infant was receiving $90 \mathrm{ml} / \mathrm{kg} /$ day of milk.

Group C received parenteral nutrition alone until ventilatory support, including CPAP, was no longer required. Milk feeding was then introduced, increased, and fortified as for group TF.

The regimen of parenteral nutrition used for both groups was the same and consisted of a solution of amino acids (Vaminolact, Pharmacia-Upjohn), 10\% dextrose, electrolytes, trace minerals and water soluble vitamins, plus a fat emulsion Intralipid $20 \%$ (Pharmacia-Upjohn) with added fat soluble vitamins. Parenteral nutrition was started on day 2 of life and the content was incrementally increased to a maximum on day 7 . The rate of increase and total fluid intake for both groups were matched and included that contributed by trophic feeding.

No attempt was made to blind carers to infant group allocation. It was considered both impractical and unethical to pass nasogastric feeding tubes and give sham milk feeds to infants in group C.
PART 1: ASSESSMENT OF GASTRIC EMPTYING Gastric emptying was assessed within 24 hours of the first occasion that each infant received a milk intake equal to or exceeding $90 \mathrm{ml} / \mathrm{kg} /$ day (at least a $4 \mathrm{ml} / \mathrm{kg}$ hourly bolus feed). Gastric emptying was assessed ultrasonically by serially measuring the change in the gastric antral cross sectional area (ACSA) following a feed. ${ }^{13}$ ACSA was measured by obtaining real time, ultrasound, cross sectional images of the gastric antrum with the infant lying in the right lateral position. Vertebral bodies, the aorta, and the superior mesenteric artery were used as constant anatomical landmarks to ensure the same cross sectional plane of the gastric antrum was measured on each occasion. Images were obtained using the Hewlett Packard Ultrasound Imaging System, model HP Sonos 100 , with a $7.5 \mathrm{MHz}$ probe. Software available on the machine allowed images to be frozen on the screen, the gastric antrum cross sectional circumference to be marked with a steerable cursor, and the calculation of the ACSA.

Before each study the stomach contents were aspirated up the nasogastric tube. The ACSA was measured before the test feed. A bolus feed of $4 \mathrm{ml} / \mathrm{kg}$ of whichever milk the infant was receiving was given over a period of 10 minutes. Immediately the feed was completed the ACSA was remeasured. ACSA was subsequently measured at 10 minute intervals until 30 minutes had elapsed, and then at 15 minute intervals until 2 hours after the feed, or the pre-feed value was reached. Fifty per cent $\triangle \mathrm{ACSA}$, defined as the time taken for the ACSA to decrease by half of the maximum change seen during gastric filling, was calculated. This value provides a simple, single measurement of gastric emptying allowing subsequent infant comparison. ${ }^{13}$

\section{PART 2: ASSESSMENT OF WHOLE GUT TRANSIT} TIME

WGTT was measured by timing the transit of the marker carmine red through the gut. Carmine red is an inert non-absorbed dye, which is bright red in colour and readily identifiable in neonatal stools. ${ }^{16-18}$ WGTT was assessed in each infant on two occasions, at 3 weeks and at 6 weeks of postnatal age. Carmine red (125 mg) was syringed over 1 minute down a 5 or 6 French gauge nasogastric feeding tube and the time recorded. At each subsequent nappy change the nurse inspected any stool for the first presence of carmine red. Once detected, its presence was confirmed by an investigator ( $\mathrm{RM})$ and the time elapsed since administration recorded. WGTT was defined as the time between carmine red administration and its first appearance in the stool.

Carmine red was always given at about $3 \mathrm{pm}$ to minimise any effect of circadian rhythm. In infants receiving enteral feeds carmine red was given at the mid point between feeds. Nappy change frequency was at the discretion of the attending nurse, but was generally 3-4 hourly. Stool inspection was continued for a maximum of three weeks. If no carmine red was seen by this time then it was felt likely that passage had 
Table 1 Characteristics of infants at time of initial assessment for parts 1 and 2 of study: median (interquartile range)

\begin{tabular}{|c|c|c|c|c|c|c|}
\hline \multirow[b]{2}{*}{ Variable } & \multicolumn{2}{|l|}{ Part 1 of study } & \multirow[b]{2}{*}{$p$ value } & \multicolumn{2}{|l|}{ Part 2 of study } & \multirow{2}{*}{$\begin{array}{l}p \\
\text { value }\end{array}$} \\
\hline & Group TF & Group C & & Group $T F$ & Group $C$ & \\
\hline Number & 21 & 21 & & 26 & 31 & \\
\hline Male:Female ratio & $1: 1.1$ & $1: 1.3$ & $1^{\star}$ & $1: 1.8$ & $1: 1.1$ & $0.4^{\star}$ \\
\hline Gestation (weeks) & $29(28,30)$ & $29(27,30)$ & 0.9 & $29(27,30)$ & $28(26,29.5)$ & 0.3 \\
\hline Birthweight $(\mathrm{kg})$ & $1.18(0.97,1.39)$ & $1.13(0.86,1.48)$ & 0.9 & $1.04(0.9,1.37)$ & $1(0.8,1.35)$ & 0.4 \\
\hline Birthweight ratio & $0.86(0.71,0.98)$ & $0.89(0.81,1.06)$ & 0.5 & $0.86(0.73,1.01)$ & $0.98(0.77,1.16)$ & 0.3 \\
\hline CRIB score & $4(3,7)$ & $3(2,4)$ & 0.1 & $4(3,7)$ & $4(2,5)$ & 0.3 \\
\hline Postmenstrual age (weeks) & $32.9(31.7,33.9)$ & $32.7(31.9,34.3)$ & 0.8 & $32(30,33)$ & $31(29,32.5)$ & 0.3 \\
\hline Postnatal age (days) & $27(20,34)$ & $26(14,37)$ & 0.8 & 21 & 21 & \\
\hline Weight at study (kg) & $1.33(1.15,1.62)$ & $1.49(1.16,1.67)$ & 0.7 & $1.4(1.2,1.63)$ & $1.52(0.95,1.68)$ & 0.2 \\
\hline Feed amount (ml) & $6(4,7)$ & $5(4,6)$ & 0.3 & $9(7,10)$ & $8(7,10)$ & 0.3 \\
\hline Days to full milk feeds & $26(23,31)$ & $31(16,40)$ & 0.6 & $29(22,40)$ & $34(26,48)$ & 0.1 \\
\hline Antenatal dexamethasone (doses) & $1.5(1,2)$ & $2(0,2)$ & 0.5 & $1(0,2)$ & $2(0,2)$ & 0.6 \\
\hline Postnatal dexamethasone (days) & $14(0,26.5)$ & $5(0,31)$ & 0.6 & $14(0,21)$ & $21(0,45)$ & 0.1 \\
\hline $\begin{array}{l}\text { Breast milk:preterm formula milk ratio } \\
\text { (majority feed) }\end{array}$ & $1: 1.1$ & $1: 1.63$ & $0.8^{\star}$ & $1: 0.8$ & $1: 1.2$ & $0.6^{\star}$ \\
\hline
\end{tabular}

^ Fisher's exact test

been missed and no value for WGTT was recorded.

DATA ANALYSIS

Statistical analysis was performed using the computer software program Excel 5.0 (Microsoft Corporation). The two tailed Student's $t$ test was used for comparison of means of variables approximating a normal distribution. For non-normal variables, the Mann-Whitney U test was used. Fisher's exact test was used for categorical variables. A p value of less than 0.05 was considered significant. Where appropriate the mean difference or median difference, with 95\% confidence interval, was also calculated using the software Confidence Interval Analysis (BMJ Publishing Group).

\section{Results}

Fifty one infants were recruited into part 1 of the study. Seventy infants, including all 51 in part 1 , were recruited into part 2 . There was no apparent difference in the spectrum of complications suffered as a result of their prematurity. No infant was noted to have any clinically significant adverse event directly attributable to either parenteral or enteral feeding.

PART 1: GASTRIC EMPTYING

Twenty five infants were recruited into group $\mathrm{TF}$, of whom 21 were assessed. Twenty six infants were recruited into group C, of whom 21 were assessed. Nine infants died before becoming eligible for study. The baseline char-

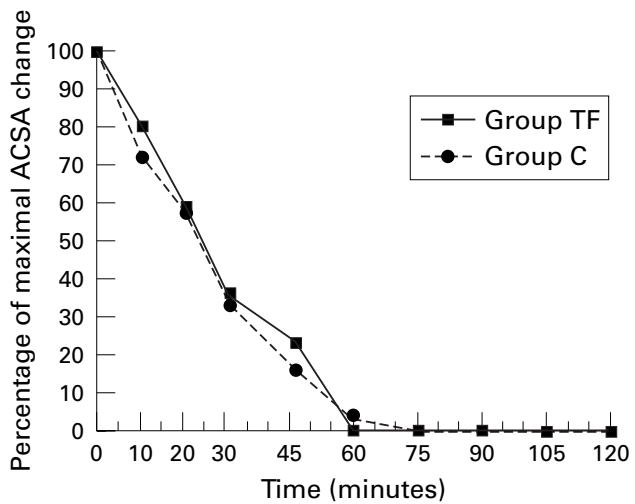

Figure 1 Median postprandial decrease in ACSA as a percentage of maximum postprandial value. acteristics of the two groups are summarised in table 1 . No significant difference was noted in any variable, including the CRIB prognostic score for mortality. ${ }^{19}$

Trophic feeding of infants in group TF was generally well tolerated but had to be omitted or reduced on 166 days out of a possible 457 . Feeds were omitted because of the need for CPAP (97 days), abdominal distension (12), recurrent apnoea (12), non-absorbence of milk (15) or worsening illness (32). The median weekly energy intake was higher in group TF during each week before study, but this difference was only significant during the third week (756 kcal/kg/week compared with $707 \mathrm{kcal} / \mathrm{kg} /$ week).

Infants tolerated measurement of gastric emptying well. No ill effects from the procedure were noted. The median gastric emptying curve for each group is shown in fig 1 . The median (interquartile range) $50 \% \triangle \mathrm{ACSA}$ for group TF was 24.7 (17.5-50.8) minutes. This was not significantly different from that measured for group C, 23.4 (16.4-35.1) minutes $(p=0.6)$, median difference $(95 \%$ confidence interval) was $2.6(-5.9,13.9)$ minutes.

PART 2: WHOLE GUT TRANSIT TIME

Thirty three infants were randomised into group TF and 37 into group C. Twenty six infants and 31 infants were studied at three weeks, respectively. Thirteen infants died before study. A further 25 infants were transferred before the second study at six weeks, resulting in 15 infants from group TF and 17 infants from group $\mathrm{C}$ being assessed at this time. No ill effects from administration of carmine red were noted. The baseline characteristics of the two groups at 3 weeks of age are summarised in table 1. Again no significant differences were noted between groups. There remained no significant differences at 6 weeks of age (data not shown).

Trophic feeding of infants in group TF had to be omitted or reduced on 304 days out of a possible 526. Feeds were omitted because of the need for CPAP (201 days), abdominal distension (20), recurrent apnoea (26), nonabsorbence of milk (47) or worsening illness (20). The median weekly energy intake was higher in group TF during each week before study, but this difference was again only 


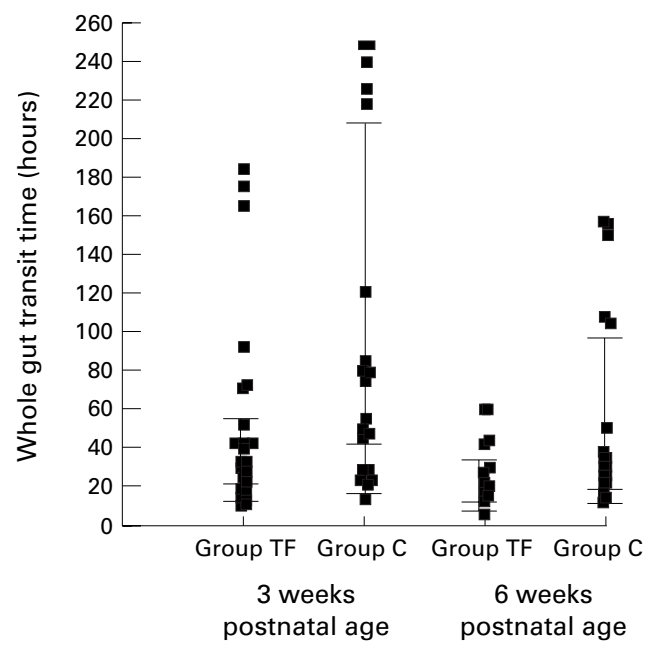

Figure 2 Individual whole gut transit time at 3 and 6 weeks of postnatal age. Broad horizontal bars represent median WGGT; narrow horizontal bars represent interquartile ranges: $p<0.05$ at both 3 and 6 weeks.

significant during the third week (749 kcal/kg/ week compared with $700 \mathrm{kcal} / \mathrm{kg} /$ week).

A comparison of WGTTs measured in each group is shown in fig 2 . The median (interquartile range) WGTT for group TF at 3 weeks was $32(21,61.5)$ hours. This was significantly less than the $49(26,218)$ hours for group C, median difference $(95 \%$ confidence interval) $-13(-47,-0.1)$ hours, $\mathrm{p}=0.04$.

For both groups the median WGTT at 6 weeks was less than that at 3 weeks. Median WGTT at 6 weeks was $21(17,42.5)$ hours which was again significantly less than for group C, 33 (23.8, 106.5) hours, median difference $-12.5(-44,-0.5)$ hours, $\mathrm{p}=0.04$.

\section{Discussion}

Trophic feeding enhances the development of motility patterns at the gastroduodenal junction. ${ }^{11}{ }^{12}$ Our study shows, for the first time, that whole gut transit is more rapid in infants receiving trophic feeding.

The technique of using carmine red to measure WGTT is simple but relatively crude and has a wide variability. ${ }^{16-19}$ Despite this, a large difference in WGTT was demonstrated, emphasising the effect of trophic feeding on intestinal motility.

The previous mean WGTT measured by Ernst et al, using carmine red in preterm infants, was 30 hours, ${ }^{16}$ longer than that found in term infants. ${ }^{17}{ }^{18}$ In our study transit times at 6 weeks and particularly those recorded at 3 weeks were longer than measured in the above studies. The discrepancy may be due to the healthier status of the previously studied infants. All this data taken together suggest that WGTT decreases with increasing postmenstrual age, a notion supported by previous data on the development of gastrointestinal motility. ${ }^{20} 21$

Several studies have shown that subsequent milk tolerance is improved by trophic feeding..$^{7-11}$ Our study showed no effect on gastric emptying. Enhancement of intestinal motility seems to be solely responsible for the improved tolerance.
It is perhaps surprising that gastric emptying was unaffected while trophic feeding had a significant influence on intestinal motility. The ultrasound technique used for assessing gastric emptying has been used successfully before to detect a difference in the emptying of comparable feed volumes of EBM and formula milk in preterm infants. ${ }^{14}$ It is unlikely, therefore, that the small feed volumes used prevented detection of an effect. However, gastric emptying could only be assessed once infants were tolerating $90 \mathrm{ml} / \mathrm{kg} /$ day of milk. Unfortunately, no alternative technique has been shown to be able to measure smaller volumes. Any advantage from trophic feeding might no longer be evident once infants tolerate this much milk.

Postprandial motor activity is thought to be non-propulsive, and fasting motor activity, characterised by the migrating motor complex, is responsible for aboral movement of intestinal luminal contents. ${ }^{22}$ Trophic feeding, therefore, is likely to accelerate intestinal transit by enhancing the migrating motor complex. The mechanisms by which trophic feeding exerts its influence are unknown. Trophic feeding is responsible for surges in the plasma concentration of several enteric hormones and peptides which are known to alter gut motilitymotilin, gastrin, neurotensin, and peptide $Y^{2} .^{23}$ Trophic feeding may cause stimulation of the enteric nervous system, either directly via neuroreceptors or indirectly via hormone release. In the preterm intestine, trophic feeding can directly stimulate motor activity, independent of hormonal responses. ${ }^{24}$

Other factors known to alter fasting intestinal motor activity include antenatal steroid exposure, illness, dietary fibre, drugs, bacterial volume, metabolites and endotoxins, nutrient absorption, dietary osmotic load and bile salts. Most of these seemed to be controlled for but it is possible that trophic feeding influenced several of these.

It was surprising that a difference still existed between groups at 6 weeks of postnatal age. Almost all infants could tolerate full milk feeds by 6 weeks and median postnatal age at 6 weeks was 34 weeks for each group. Development of the fasting migrating motor complex is incomplete at this postnatal age. ${ }^{21}{ }^{21}$ Despite both groups tolerating full feeds, the effect on motility development due to trophic feeding was still evident at this age. A possible explanation is that motilin is still significantly increased up to 3 weeks in ill VLBW infants fed enterally as opposed to total parenteral nutrition. ${ }^{25}$

In this study the volumes of trophic feeding were small and many infants, reflecting their clinical instability, received less milk than intended. This suggests that the gut is very sensitive to the presence of milk. Although direct comparison was not made, EBM and formula milk in this study seemed to have similar effects on WGTT. This suggests that the component(s) responsible for altering motility are present in both.

Trophic feeding can have a significant effect on motility of the developing intestine. No adverse effects were attributable to trophic feeding. These data support the use of trophic 
feeding in the critically ill preterm infant receiving parenteral nutrition.

This work was generously supported by a grant from the Nutricia Research Foundation.

We are indebted to the staff members of the regional neonatal intensive care unit at St James's University Hospital, Leeds for their help and cooperation.

1 McClure RJ, Chatrath MR, Newell SJ. A survey of the variety and changing trends in feeding policies for ventilated preterm infants

2 Yu VYH, James B, Hendry P, MacMahon RA. Total parenteral nutrition in very low birthweight infants: a controlled trial. Arch Dis Child 1979;54:653-61.

3 Glass EJ, Hume R, Lang MA, Forfar JO. Parenteral nutrition compared with transpyloric feeding. Arch Dis Child 1984;59:131-5.

4 Unger A, Goetzman BW, Chan C, Lyons AB, Miller MF. Nutritional practices and outcome of extremely premature infants. Am ₹ Dis Child 1986;140:1027-33.

5 Greene HL, McCabe DR, Merenstein GB. Protracted diarrhea and malnutrition in infancy: Changes in intestinal morphology and disaccharidase activity. Gastroenterology 1974;67:975-82.

6 Orenstein SR Enteral versus Parenteral therapy for intractable diarrhea of infancy. F Pediatr 1986;109:277-86.

7 Dunn L, Hulman S, Weiner J, Kliegman R. Beneficial effects of early enteral feeding on neonatal gastrointestinal function: Preliminary report of a randomised trial. 7 Pedi-

8 Slagle TA, Gross SJ. Effect of early low-volume enteral substrate on subsequent feeding tolerance in very low birth weight infants. $\mathcal{F}$ Pediatr 1988;13:526-31.

9 Meetze WH, Valentine C, McGuigan JE, Conlon M, Sacks $\mathrm{N}$, Neu J. Gastrointestinal priming prior to full entera nutrition in very low birth weight infants. $\mathcal{F}$ Pediatr Gastroenterol Nutr 1992;15:163-70.

10 Troche B, Harvey-Wilkes K, Engle WD, et al. Early minimal feedings promote growth in critically ill premature infants. Biol Neonate 1995;67:172-81.

11 Berseth CL. Effect of early feeding on maturation of the preterm infant's small intestine. F Pediatr 1992;120:947-
12 Bisset WM, Watt J, Rivers RPA, Milla PJ. The postprandial motor response of the small intestine to enteral feeds in the preterm human infant. Arch Dis Child 1989;64:1356-61.

13 Newell SJ, Chapman S, Booth IW. Ultrasound assessment of gastric emptying in the preterm infant. Arch Dis Child 1993;69:32-6.

14 Ewer AK, Durbin GM, Morgan MEI, Booth IW. Gastric emptying in preterm infants. Arch Dis Child 1994;71:F247.

15 McClure RJ, Newell SJ. The effect of fortifying breast milk on gastric emptying. Arch Dis Child 1996;74:F60-2.

6 Ernst JA, Rickard KA, Neal PR, et al. Lack of improved growth outcome related to non-nutritive sucking in very low birth weight premature infants fed a controlled nutrient intake: A randomised prospective study. Pediatrics 1989;83:706-16.

17 Fomon SJ, Filer LJ. Milk and formulas. In: Fomon SJ, ed. Infant nutrition. Second edn. Philadelphia: WB Saunders, 1974:359-407.

18 Rubaltelli FF, Largajolli G. Effect of light exposure on gut transit time in jaundiced newborns. Acta Paediatr Scand $1973 ; 62: 146-8$

19 Cockburn F, Cooke RWI, Gamsu H, et al. The CRIB (clinical risk index for babies) score: a tool for assessing initial neonatal risk and comparing performance of neonatal intensive care units. Lancet 1993;342:193-8.

20 Bisset WM, Watt J, Rivers RPA, Milla PJ. Ontogeny of fasting small intestinal motor activity in the human infant. Gut 1988;29:483-8.

21 Berseth CL. Gestational evolution of small intestine motility in preterm and term infants. F Pediatr 1989;115:646-51.

22 Kerlin P, Zinsmeister A, Phillips S. Relationship of motility to flow of contents in the human small intestine. Gastroenterology 1982;82:701-6.

23 Lucas A, Bloom SR, Aynsley-Green A. Gut hormones and "Minimal enteral feedings". Acta Paediatr Scand 1986;75:719-23.

24 Berseth CL, Go VLW. Post-prandial response of intestinal motor activity and gut hormones in preterm infants receiving their first feeding with milk or water. Gastroenterology 1991;98:A396.

25 Shulman DI, Kanarek K. Gastrin, motilin, insulin, and insulin-like growth factor-1 concentrations in very-lowbirth-weight infants receiving enteral or parenteral nutrition. F Parent Ent Nutr 1993;17:130-3. 